\title{
ANALYSIS OF SODIUM WITH SPARK SOURCE MASS SPECTROMETER
}

\author{
By
}

H. FARRAR IV

C. H. KNOX

\section{LEGL NOTICE}

Ths report was prepared as an account of Government sponsored work. Neither the United A. Makes any warranty or representation expres behalf of the Commission:

racy, completeness, or usefulness of the informatressed or impled, with respect to the accuof any information, apparatulness of the information contaned in this report, or that the use privately owned rights; or

B. Assumes any liabilities with respect to the use of, or for damages resulimg from the
se of any information, apparatus, mathod, or prot infinge As used in the above "per, method, or process disclosed in this report.

ployee or contractor of the Commissting on behalf of the Commission" includes any emsuch employee or contractor of the Commisemployee of such contractor, to the extent that dissemmates, or provides access to, any inform, or employee of such contractor prepares with the Commission, or his employ an mormation pursuant to his employment or contract

\section{ATOMICS INTERNATIONAL}

A DIVISION OF NORTH AMERICAN ROCKWELL CORPORATION

CONTRACT: AT(04-3)-701

ISSUED: JUNE 21, 1968 


\section{DISCLAIMER}

This report was prepared as an account of work sponsored by an agency of the United States Government. Neither the United States Government nor any agency Thereof, nor any of their employees, makes any warranty, express or implied, or assumes any legal liability or responsibility for the accuracy, completeness, or usefulness of any information, apparatus, product, or process disclosed, or represents that its use would not infringe privately owned rights. Reference herein to any specific commercial product, process, or service by trade name, trademark, manufacturer, or otherwise does not necessarily constitute or imply its endorsement, recommendation, or favoring by the United States Government or any agency thereof. The views and opinions of authors expressed herein do not necessarily state or reflect those of the United States Government or any agency thereof. 


\section{DISCLAIMER}

Portions of this document may be illegible in electronic image products. Images are produced from the best available original document. 
Abstract $0.0 \cdot 0.0 .0 .0 .0 .0 .0 .0 .0 .0$ Page

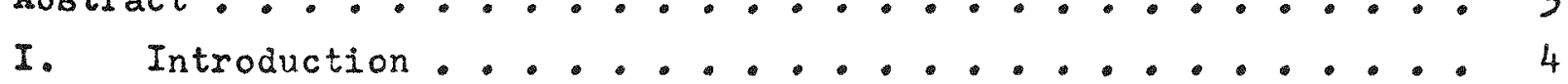

A. General Introduction .............. 4

B. Spark Source Mass Spectrometer .......... 4

C. Relative Sensitivity Factors ........... 5

D. Early Alkali Analyses ........... 7

II. Results ................... 7

A. Analysis of Potassium in Gold Fo11......... 7

B. Analysis of Potassium Chloride .......... 8

C. Mass Spectrometer Modification .......... 9

D. Method of Data Reduction ............. 13

E. Analysis of Metallic Sodium ........... 13

F. Discussion of Results ........... 15

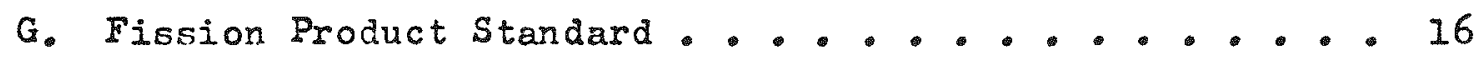

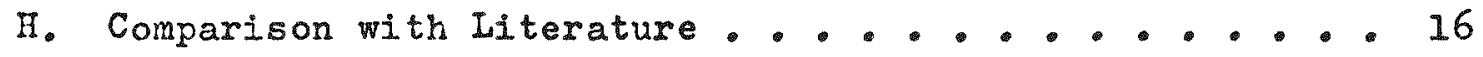

III. Plans for Future Work ............. 19

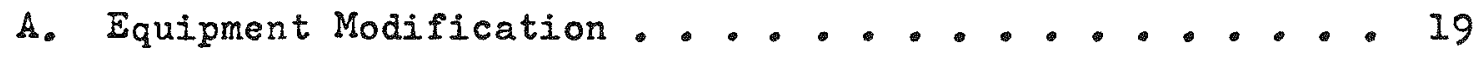

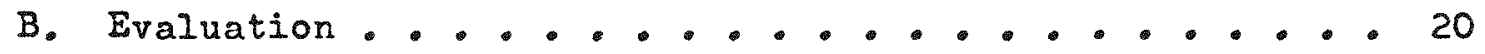

IV. Acknowledgements .................... 21

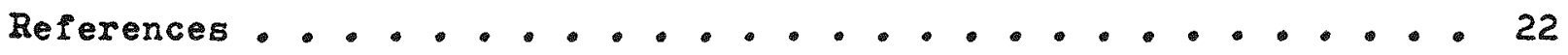

FIGURES

1. Mass Spectrometer Sodium Loading Manipulator ....... 10

2. View of Loading Manipulator Housing and Source Controls .. II

3. View of Source Interior Showing Reservoir and Copper

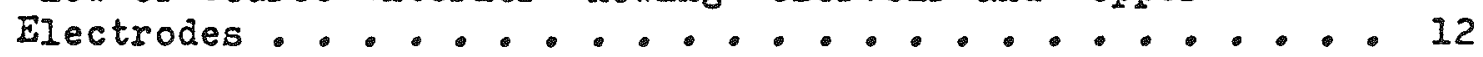

4. Low Mass Portion of Fission Product Standard Photoplate - 17

5. High Mass Portion of Fission Product Standard Photoplate - 18 


\begin{abstract}
A spark source Mattauch-Herzog mass spectrometer has been applied to the analysis of sodium metal. Modifications to the source housing allowing the sodium to be introduced to the electrodes under vacuum have resulted in the elimination of unwanted oxides and polymers. Iiquid nitrogen cooling of the sodium prevents melting during the analysis. The results indicate that thermal ionization does not contribute to the sodium ion beam and that the sodium metal and the impurities within it behave like other metals during RF spark analysis. Efforts to more effectively control the mass spectrometer operating conditions and to measure the sensitivity for the different elements have commenced. It appears likely that with improved techniques now planned, analyses of sodium to impurity levels less than $0.1 \mathrm{ppm}$ will be brought up to the level of spark source mass spectrometer work presently performed on other metals
\end{abstract}




\section{INTRODUCTION}

\section{A. General Introduction}

The true advantages of the sparks source mass spectrometer (SSMS) over other instruments are realized when general analyses are performed to determine the entire elemental composition of a sample. A single analysis of a solid takes between $1 / 2$ hour and 4 hours. In most cases the result is that all elements present in concentrations greater than 10 parts per biliion (and sometimes less) are displayed on a photoplate. The fact that every element is shown whether it is of interest or not, can result in the determination of elements not thought to be present and which there-fore would have remained undetected by other techniques. Final data processing of course need be performed only on those elements of interest.

Over the past six years a number of improvements to the methods of sample handing and photoplate data reduction have reduced the uncertainties of concentrations in an analysis from a factor of 10 to a much more acceptable value of $\pm 30 \%$ or lower for some elements. The lower uncertainties are obtained by comparing the results with an analysis of a similar "standard" whose impurity concentrations are known.

Sodium and potassium have presented problems due to sample oxidation and interpretation difficulties. A few attempts to analyze these materials have been little better than qualitative, and no concerted effort had been made until recently to devise ways to overcome the problems and bring alkali analyses up to the level of other spark source work.

\section{B. Spark Source Mass Spectrometer}

The mass spectrometer used in this work is the JEOLCO Model JMS-OIB with spark source and photographic detection. Because the spark produces ions with an energy spread of several hundred volts, the mass spectrometer must have both energy and direction focusing (double focusing). The Mattauch-Herzog configuration of electrostatic field followed by magnetic field fulfills this requirement with the aditional advantage that all masses over a range from mass $\mathrm{m}$ to mass $36 \mathrm{~m}$ are focused simultaneously on a plane. Photoplate detection is usually used because the exratic spark lluctuation makes integration of the beam attractive.

$$
\text { AI-AEC-MEMO- } 12719
$$


The source is normally operated with a I Miz RF spark operating at a $10 \overline{\mathrm{KH}}$ repetition rate with $25 \mathrm{Kv}$ ion beam acceleration. The electrostatic analyzer has spherical surfaces with a radius of $200 \mathrm{rm}$. The 380 $\mathrm{mm}$ long photoplate is situated immediately behind the exit slit of the magnet. Eight photoplates can be loaded into individual lightutight cassettes and placed in the "prepump" vacuum chamber for individual insertion into the focal plane. Thirty-two exposures can be placed on a plate. The main, $\alpha$ and $\beta$ slit widths may all be adjusted from outside the vacuum housing by micrometer, and in addition, the angle of the main slit and the lateral positions of the $\alpha$ and $\beta$ slits may similarly be adjusted by micrometer.

The vacuum in the electrostatic and magnetic analyzer regions is normally better than $1 \times 10^{-8}$ tors during sparking of a sample. The source region is pumped with a $6 "$ oil aiffusion pump which produces a vacuum of $3 \times 10^{-7}$ torr within 3 minutes of closing the front flange on which all source controls are mounted. The source is normally operated at a vacuum of less than $1 \times 10^{-7}$ torr. This instrument was installed at Atomics International, Canoga Park, Los Angeles in mid-1965.

\section{Relative Sensitivity Factors}

It was early recognized that the great feature offered by the RF spark is that all elements are ionized approximately equally. Therefore, the resulting ion beam is essentially made up of the elemental components of the material which is being vaporized by the spark. The ionized elements appear principally with a single charge, but double, triple and other multiple charged ions appear in amounts decreasing by a factor of 3 to 5 for each increase in charge number. Impurity concentrations are generally determined by comparing the density of the singly charged impurity image or Iine on the photoplate with the density of the singly charged matrix line. Corrections for the abundances of the isotopes used, and sometimes for variation in line-width are then applied. The resulting estimate of the concentration can be compared with the known concentration 
by analyzing a standard sample. The difference in result can be applied as a correction factor or "relative sensitivity factor" (RSF), which is the "concentration determined by the analysis" divided by the "true concentration." Thus the RSF is a measure of the enhancement of the detected element compared with some other element whose factor is assumed or set equal to unity. Many standards have been $r$ un in different laboratories. RSF's have been known to vary from day to day (althouch this could be interpreted as an inhomogeneity within the standard); and from instrument to instrument. Nevertheless, certain elements (tin, lead, sodium, potassium and others) always exhibit high factors. When no standard of the same material or with the required impurity is available, the RSF is either assumed to be unity or is estimated from similar elements in similar matrices. Willardson and Sochal at Bell \& Howell Research Center, Pasadena, use an empirical formula for estimating the RSF which includes the ionization potential to the power of 3.3 .

Much of the effort in spark source mass spectrometry is devoted to obtaining the RSF's, for their determination reduces the uncertainity from a factor of 3 or more in some cases, to the $30 \%$ or less range. Careful control of the sparking parameters, RF power and spark position can improve the reproducibility of results much further. The uncertainty of the results of an analysis is in general a constant percentage of the concentration value because most of the uncertainty is in the RSF, and this is largely independent of impurity concentration. For this reason the spark source determination of a major component such as chromium in stainless steel would be unattractive if there were a $30 \%$ uncertainty whereas the same $30 \%$ uncertainty at the $20 \mathrm{ppb}$ level would be quite acceptable. 
D. Early Alkali Analyses

Swift ${ }^{2}$ and others at Associated Electrical Industries. Manchester, England were the first to analyze lithium. To prevent sample melting during the sparking, they cooled their sample holders with liquid nitrogen. The lithium was transferred in a high purity argon atmosphere. Apparently surface contamination was removed satisfactorily by "pre-sparking" or effectively removing the surface layer. The results were no more than semi-quantitative since no attempt was made to determine RSF's.

Kuptsis ${ }^{3}$ at IBM Research did some sodium analyses with a SSMS. He prepared the sample by cutting the sodium with a razor blade in a nitrogen atmosphere to form two electrodes which were then inserted in clamps in the mass spectrometer source. He observed that the $\mathrm{Na}^{+}$beam was very large with respect to the $\mathrm{Na}^{++}$beam compared to the same species for other elements even though the electrodes were liquid nitrogen cooled. He then assumed, as did others, that the additional process of thermal ionization was contributing heavily to the formation of the $\mathrm{Na}^{+}$beam. Thermal ionization will not however produce doubly charged ions. Thus Kuptsis was reluctant to base his analyses by comparing singly charged impurity beams (which were presumably formed by the "regular" RF processes) with the singly charged sodium beam which was formed another way. To overcome this be compared the singly charged impurities with doubly charged sodium $\left(\mathrm{Na}^{++}\right)$and assumed that the $\mathrm{Na}^{++}$was "depressed" by a factor of $5(\mathrm{RSF}=0.2)$, as most other elements are with respect to their singly charged species. Results of this work were useful in that they give relative values from analysis to analysis, but no real effort was undertaken to make the values absolute.

\section{RESULTS}

A. Analysis of Potassium in Gold Foil

Initial experiments at AI to analyze alkalis with the SSMS used samples of potassium encased and sealed between two gold foils. Each foll was then bent so that a solid gold counter - electrode "probe" could initiate a spark to the center of the foil in the source.

AI-AEC-MEMO-12719 
A large enhancement of the $\mathrm{K}^{+}$beam with respect to the $\mathrm{K}^{++}$beam was noted, alons with the appearance of numerous molecules such as $\mathrm{KO}^{+}$, $\mathrm{KOH}^{+}$; $K_{2} O H$, etc. which are thought to be the result of potassium oxidation through cracks in the gold. The non-reproducibility of the sparking conditions, the bulk of the total sample, and the variation in the contribution to the ion beam from the gold and alkali made this method unattractive to pursue.

The conclusion from this early work was that in order to obtain meaningful alkali analyses, the sample shape, size and the position of sparking wust be optimized from the mass spectrometric point-of-view. Although it is possible to spark awkward shaped samples designed for convenience of vacuum preparation, the interpretation of the results is very difficult.

B. Analysis of Potassium Chloride

As an alternative method to analyzing metallic alkali, an experiment was performed to analyze the impurity content of some potassium chloride powder compressed to form a solid electrode. When the RF voltage was applied between the salt and a gold counter-electrode, a glow appeared at the end of the electrode within the salt instead of a rormal spark discharge. The resulting ion beam consisted of $K, C I$, Au and the impurities in the salt and multiple combinations such as $\mathrm{CrK}^{+}, \mathrm{FeCl}^{+}, \mathrm{InKCI}^{+}$ AuHCI, etc. At least one ion beam occurred at every mass number on the photoplate. At many mass positions hydrocarbons appeared, but they were usually easily resolved from their isobaric isotopes. Molecules are not usually seen with an RF spark but are characteristic of thermal ionization. With thermal ionization, the basic assumption of equal sensitivity for all elements is completely invalid, and therefore extensive calibration of the machine would become necessary with the probability that the results would not be reproducible. A way of obtaining a regular RF spark would be to mix and compress the salt with ultrapure silver powder but this was not pursued when it was found that the mass spectroneter suffers from severe "memory" problems after salt analyses, even after a regular cleaning of all source parts. 
C. Mass Snectrometer Modification

In order to transfer the sodium into the mass spectrometer without sodium oxidation, the loading manipulator shown in Figures 1 and 2 was installed on the source housing. The sodium which is to be analyzed for impurity content is loaded under argon or in a vacuum into vacuum-tight stainless steel vials. A vial is then secured in the manipulator assembly which is then evacuated along with the mass spectrometer source. The long rod which is operated through bellows and O-rings and which has suitable removable end-tools is used to open the vial, scoop up a small amount of sodium and wipe this onto the ends of two suitably placed copper electrodes in the mass spectrometer source shown in Figure 3.

A major concern in SSMS analysis of alkali metal samples has been the low melting points of these materials and the consequent high vapor pressures at modest temperatures. It is important that once a small portion of the surface is sparked, the material that is melted must be immediately vaporized. If a part of the liquid material were to remain between sparks, gross fractionation of the different elements would be expected, introducing large uncertainties to the results. Furthermore while the surface is hot, ion emission by thermal ionization could contribute to the total ion beam. To prevent this; a liquid nitrogen reservoir was designed and installed to remove the heat generated in the electrodes from the $R F$ spark. The tantalum and stainless steel electrode holders were replaced with the solid pieces of press-fitted OFHC copper shown in Figure 3. These modifications reduced the temperature of the sodium sample and nearby source parts when liquid nitrogen was added to the reservoir to minus $155^{\circ} \mathrm{C}$.

Another modification made to the source was the installation of a shutter placed over a glass shield covering the viewing window. By keeping the shutter over the glass most of the time and looking at the spark only for major adjustments, the source may remain closed for long periods enabline several analyses of sodium to be performed without the need to open the source to clean the window and consequently clean all the other

AI-AEC-MENO- 12719 


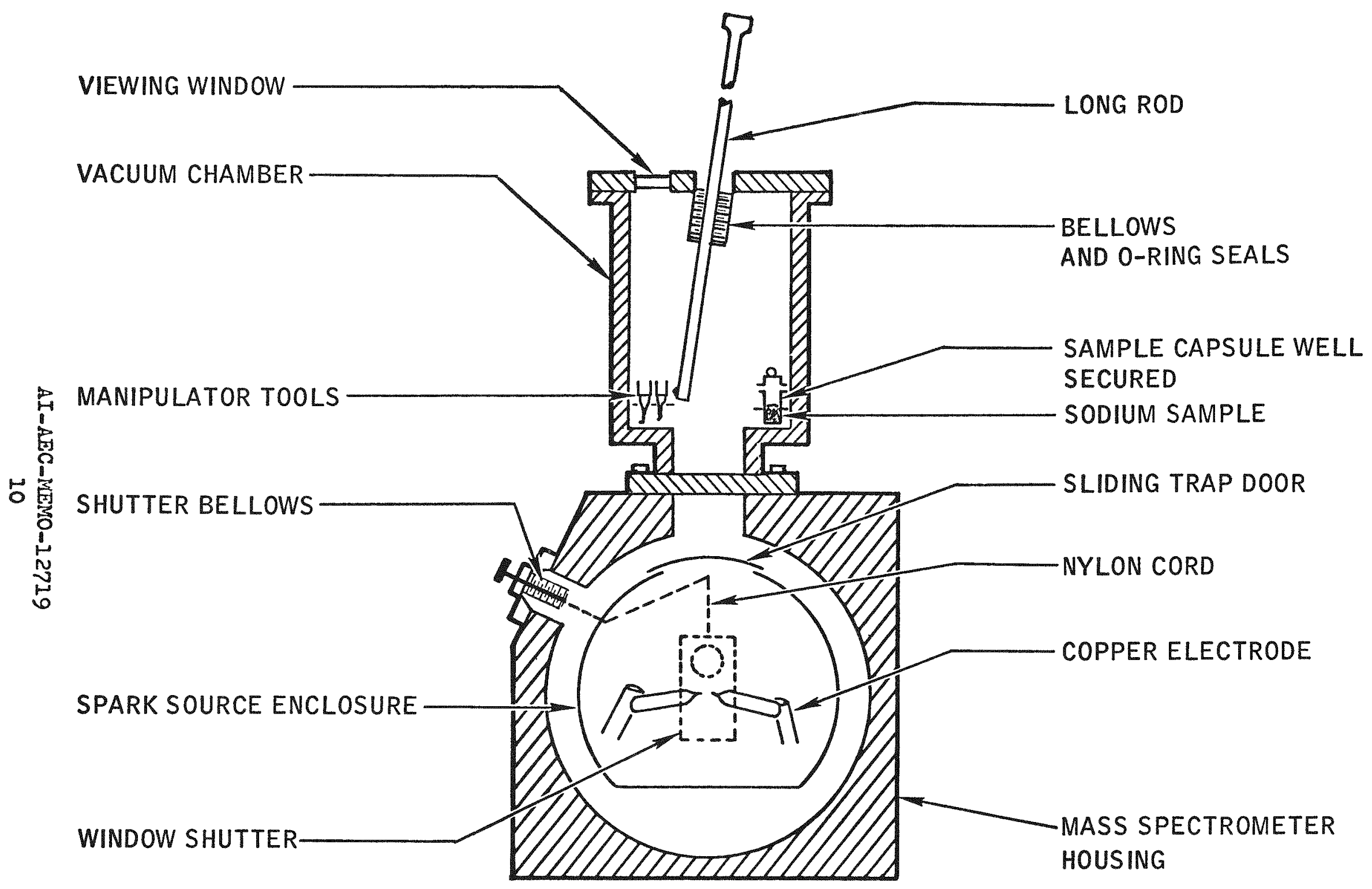

$8-\sqrt{3}-079-3$

Figure 1. Mass Spectrometer Sodium Loading Manipulator 


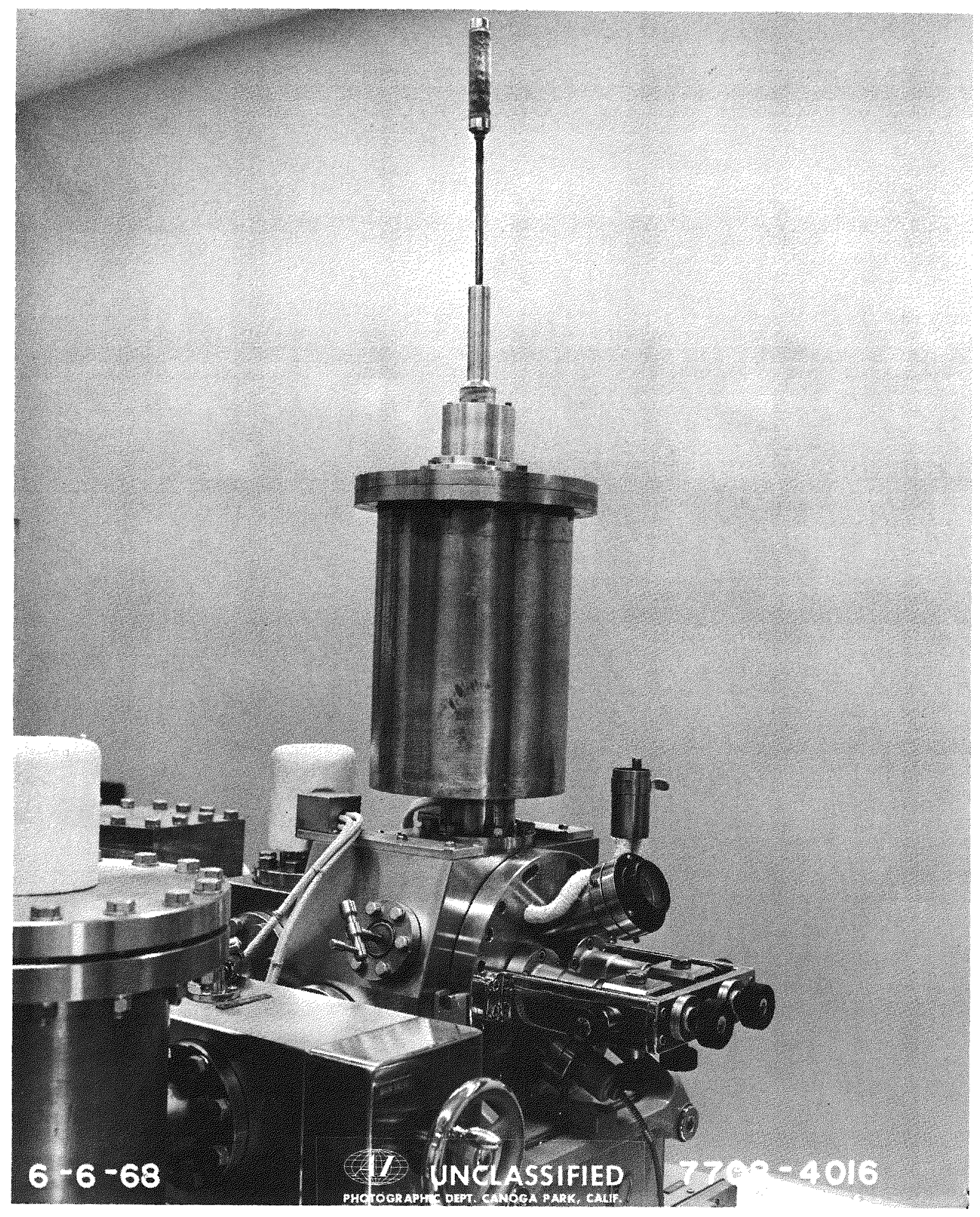

Figure 2. View of Loading Manipulator Housing and Source Controls

$$
\text { AI- } A \mathrm{E} C-M E M O-12719
$$




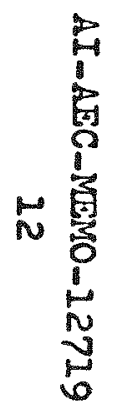

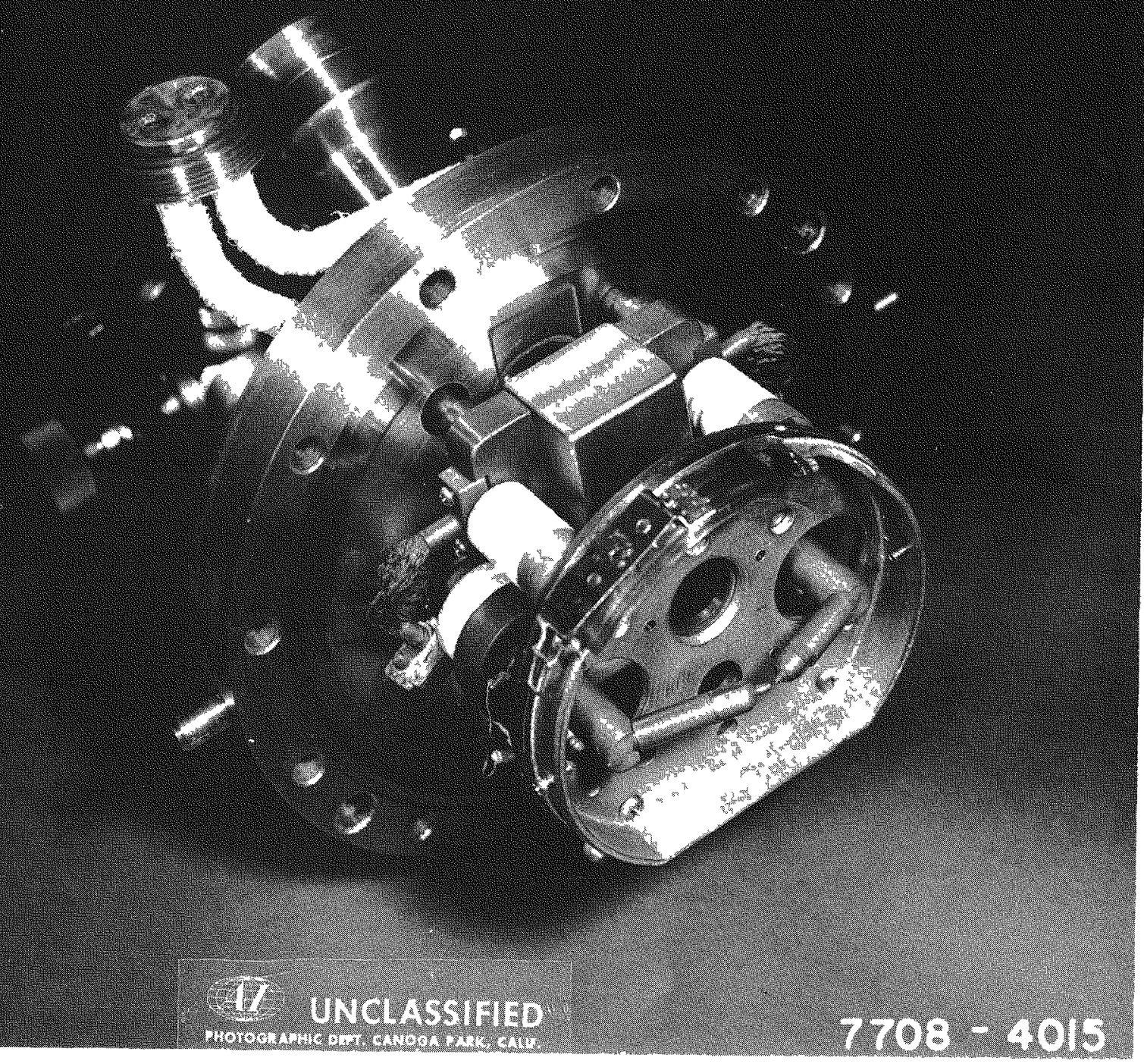

Figure 3. View of Source Interior Showing Reservoir and Copper Electrodes 
parts covered with oxidized sodium. Sample replenishment is easily accomplished by wiping on additional sodium with the manipulator rod.

D. Method of Data Reduction

Data from the mass spectrometer photoplates are processed by the "celidometer" method described by Stefani et al. 4 A series of copper snectra obtained by sparking the copper electrodes beneath the sodium are used to obtain a Churchill curve from which an emulsion calibration curve is derived. AIl other spectral lines are then converted from opti. cal density (obtained by microdensitometer) to "ion density." A computer program to perform the data processing for a digital system now on order, is being written.

E. Analysis of Metallic Sodium

The sodium used in the experiments was doped to the $125 \mathrm{ppm}$ level with the following 10 elements: $\mathrm{Ca}, \mathrm{Zn}, \mathrm{Mn}, \mathrm{Cu}, \mathrm{Ag}, \mathrm{Sb}, \mathrm{Sn}, \mathrm{H}_{\mathrm{G}}$, $\mathrm{Au}$, and Po. Since that time another "standard" was made by doping some high purity sodium with approximately $20 \mathrm{ppm}$ of the relatively soluble metals $\mathrm{Ag}, \mathrm{Au}, \mathrm{Bi}, \mathrm{In}, \mathrm{Mg}$, and $\mathrm{Pb}$.

Analyses of the sodium doped at the $125 \mathrm{ppm}$ level show first of all. that none of the oxides and other polymers appeared, indicating that the sample loading manipulator was working satisfactorily. This was in sharp contrast to photoplates obtained from sodium samples that were loaded under relatively impure argon, where polymers such as $\mathrm{Na}_{2} \mathrm{OH}_{3}^{+} \mathrm{Na}_{2} \mathrm{OH}_{2}^{+}, \mathrm{Na}_{3} \mathrm{O}^{+}$ etc. appeared in abundance. All the dopants were immediately identified along with 15 other elements including potassium and iron,demonstrating the usefulness of this method for quick survey analyses.

Experiments to see what effect the electrode modifications had, show that the conversion to the all-copper assembly at room temperature results in markedly improved spectra, giving sharper and better defined mass lines than those obtained with the previous assembly. of particular interest in the analyses of the photoplates is the fact that the

AI-AEC-MEMO- 12719 
$\mathrm{Na}^{+} / \mathrm{Na}^{++}$ratio remained high, between 500 and 1000 , and did not change significantly with electrode cooling. From this, It appears probable that the excellent conducting properties and the bulk of the copper serve to prevent the sodium from melting and that therefore further cooling makes little difference. In adition, no change in the $\mathrm{Na}^{+} / \mathrm{Na}^{++}$ratio has been observed when the spark power and therefore presumably spark temperature was varied over a considerable range. The fact that the ratio of $\mathrm{Na}^{+} / \mathrm{Na}^{++}$remained high and did not change noticeably with electrode cooling or with spark power reduction is most significant because if thermal ionization were contributing appreciably to the $\mathrm{Na}^{+}$ion beam, a sharp reduction in this ratio would be expected.

The most interesting observation was, however, that all the elements used to dope the sodium appeared in very roughly the concentrations expected from a comparison with the $\mathrm{Na}^{+}$matrix beam. This means that if the singly charged sodium beam $\left(\mathrm{Na}^{+}\right.$) were greatly enhanced by thermal ionization, as many have supposed, then to satisfy the findings on these photoplates, the impurities would have to have a similar beam enhancement (high RSF) or be present in quantities far greater than those added.

When the concentrations of the 10 added elements are normalized to the $\mathrm{Na}^{++}$beam rather than the $\mathrm{Na}^{+}$beam, they become more self-consistent. The relative concentrations of the elements displayed an average standard deviation of $21 \%$ of the concentration value. This variation, which is quite good for spark source mass spectrometry, gives the important indication that the impurities behave in sodium much as they would in ang other metallic matrix. Comparing the impurity values to $\mathrm{Na}^{++}$ reduced sample-to-sample variation but does not help much in estimating absolute concentrations unless the RSF of $\mathrm{Na}^{++}$is known. Unfortunately, RSE's of doubly and triply charged ions of many elements have been observed to vary far more than the singly charged counterparts making them undesirable to use for quantitative purposes. Therefore emphasis is being placed to find what conditions are needed to ensure a reproducible production of the $\mathrm{Na}^{+}$ion beam.

AI-AEC-MEMO-12719 
F. Discussion of Results

The first conclusion to be drawn from this is that little or no thermal ionization of the sodium occurs. Our most satisfactory explanation for the anomalous $\mathrm{Na}^{+} / \mathrm{Na}^{++}$ratio is that it is not the $\mathrm{Na}^{+}$beam that is particularly enhanced, but it is the $\mathrm{Na}^{++}$beam that is greatly depressed. The low RSF for $\mathrm{Na}^{++}$can be expected from the extra high second ionization potential of sodium due to the closed shell electron configuration. A slight enhancement of the $\mathrm{Na}^{+}$ion beam with respect to similar beams from other elements such as iron, chromium or silver might be expected from the fact that the first ionization potential of sodium is slightly lower than the others. Looking at this another way, nearly all elements, including noble gases have a ratio of second ionization potential to first ionization potential very close to 2.0 , the only exceptions being sodium (9.2), potassium (7.3) and the other alkalis. These differences are thought to be sufficient to result in the $\mathrm{Na}^{+} / \mathrm{Ma}^{++}$ ratio being over 500 whereas for most other elements the equivalent ratio rarely exceeds 5 .

The outcome of all this indicates that the $\mathrm{Na}^{+}$ion beam may be used as an internal standard for comparison with singly charged impurity beams, which is the usual method used for spark source analysis.

Some variation in the ratio $\mathrm{Na}^{+} / \mathrm{Na}^{++}$has been observed between analyses however. A quite possible explanation (that has been shown to occur for large ion beams of other elements) is that the large $\mathrm{Na}^{+}$ion beam may be sufficiently dense in some instances that the ions electrically self-repel during the flight from spark to photoplate. This will result in broader, less dense mass Iines when compared to those of smaller ion beams which accumulate for correspondingly longer times. Such a phenomenon would lessen the density of the $\mathrm{Na}^{+}$Iine (giving the opposite effect to thermal ionization) with respect to the $\mathrm{Na}^{++}$and impurity lines. Microdensitometer measurements utilizing the whole area of the lines rather than the "maximum density" measurements presently employed, are expected to do much to eliminate this source of variation. 
The fact that the concentrations of the impurities in the doped samples were more self-consistent when normalized to the $\mathrm{Na}^{++}$beam is not surprising since this beam was close in size to the impurity beams and was therefore processed by the same part of the emulsion calibration curve. The $\mathrm{Na}^{+}$beam apart from perhaps being broadened as mentioned above, produced quite a dense line on the photoplate, even with the shortest possible exposure and is processed on a less accurate part of the calibration curve. This may be overcome with the acquisition of the ion beam chopper mentioned later, which will permit shorter exposures to be made.

\section{G. Fission Product Standard}

To further the effort to understand the factors that affect the enhancement of the ion beams of various elements in the RF spark, some irradiated zirconium-uranium alloy containing fission products in the parts per million range was analyzed. Several interesting photoplates like that shown in Figures 4 and 5 have been produced clearly and simply depicting 29 fission product elements, representing every group of element in the periodic table. Because the relative concentrations of these elements are precisely known, 5 the RSF's of these elements in the matrix of zirconium may be immediately determined. Thus the behavior of xenon, krypton, and most interestingly cesium and rubidium can be compared with known "well behaved" elements such as molybdenum and silver. On the photoplate it is immediately apparent that the cesium and rubidium are somewhat enhanced witi respect to all the other elements. Although this gives no precise information on sodium or potassium, the accurate information on the RSF's of the other elements with respect to rubidium and cesium will be extrapolated to sodium if more specific information is unavailable.

H. Comparison With Literature

Progress in this work was presented informally to a group of 75 spark-source mass spectrometer users at a "Workshop Meeting" sponsored by NBS on 13-14 November 1967. The only other laboratory currently active in sodium analyses by SSMS is Westinghouse $R$ \& D Center, ${ }^{6}$ who also made a short presentation. Since that time a visit was made to their laboratory 


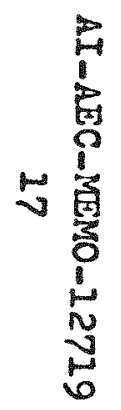

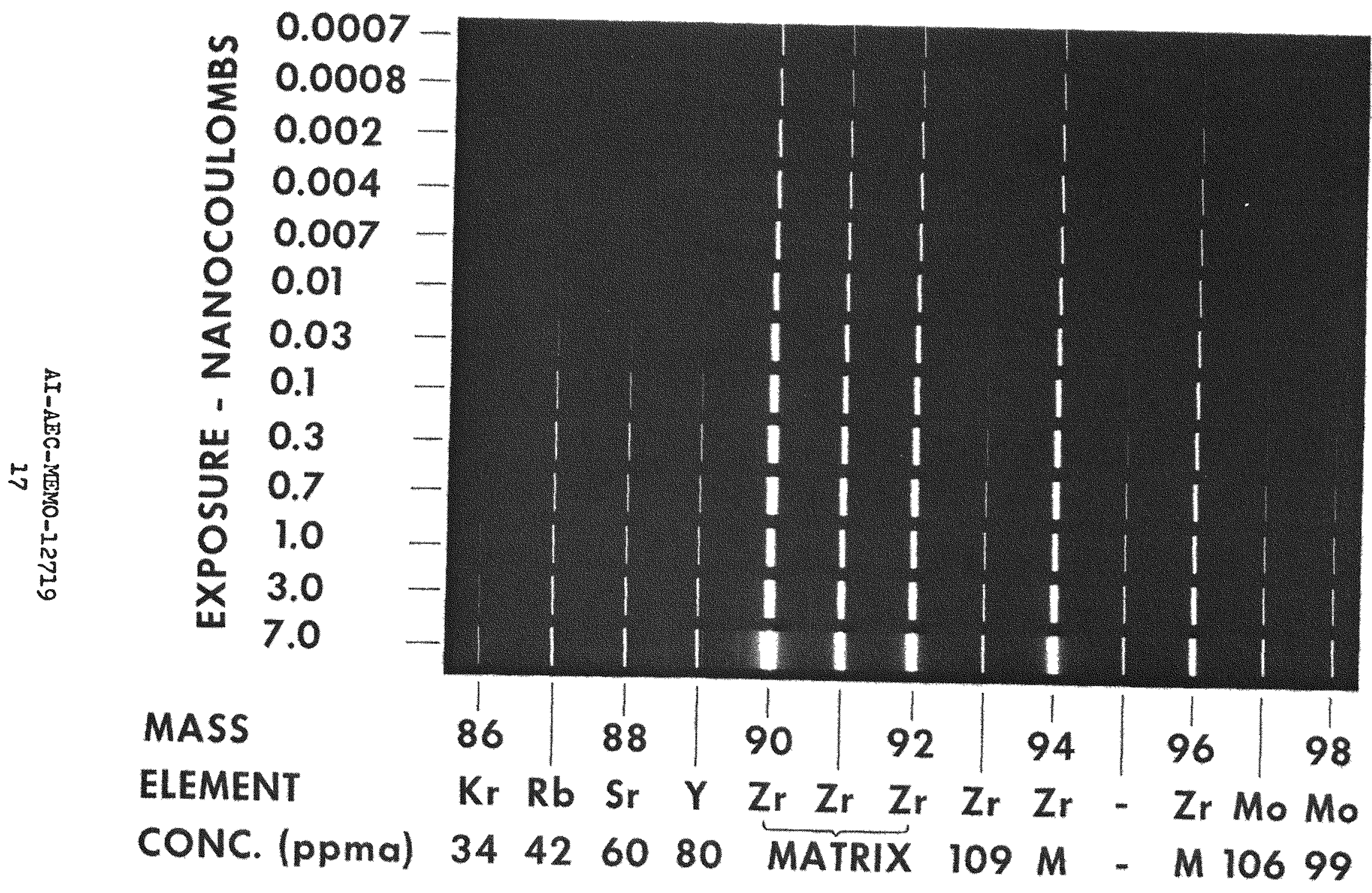




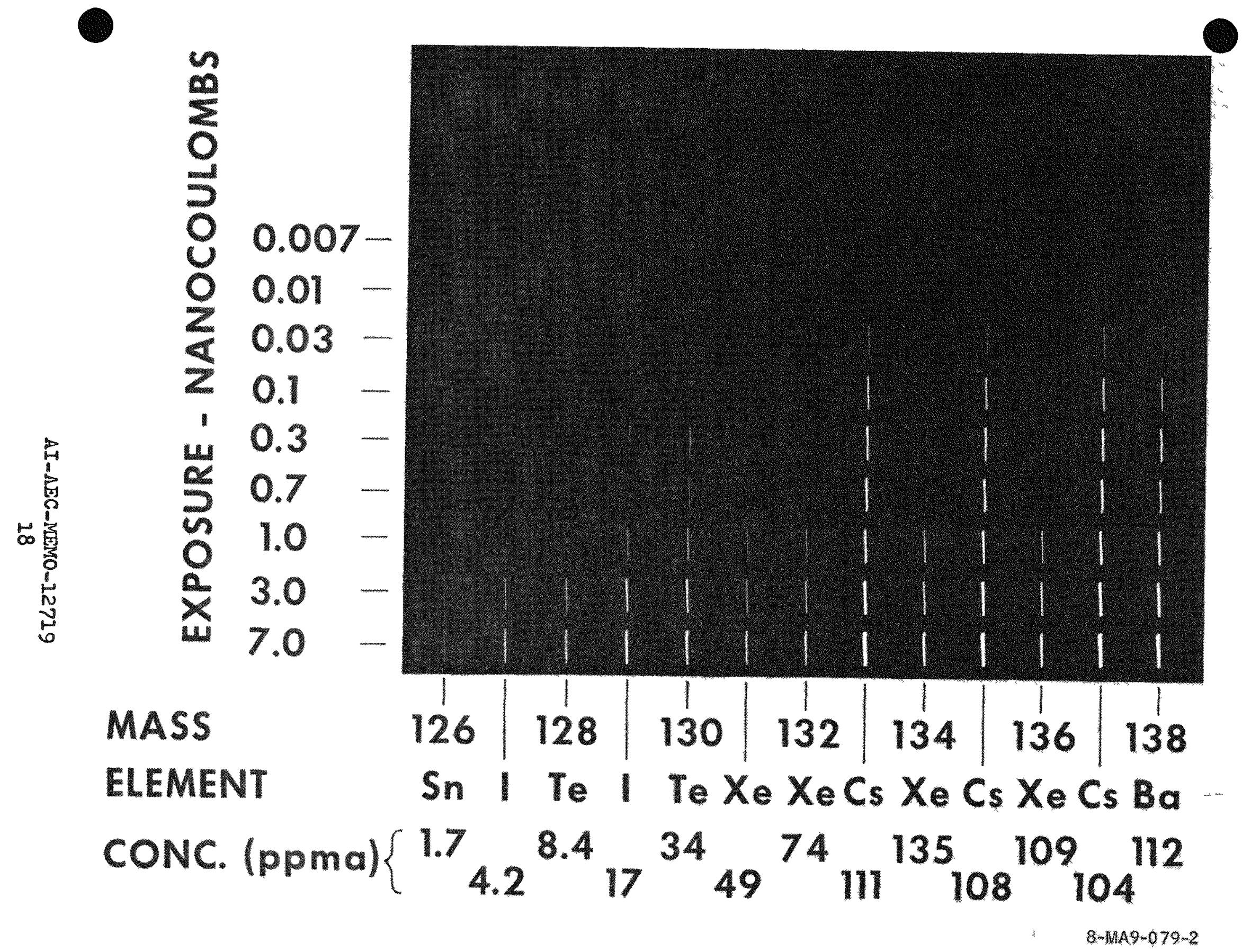

Figure 5. High Mass Portion of Fission Product Standard Photoplate 
in Pittsburgh at the time of the Annual Conference on Mass Spectrometry on May 15. 1968. Photoplates and analytical results were compared at length. They have also come to the conclusion that thermal ionization plays little or no part in the ionization of the $\mathrm{Na}^{+}$beam. They have established that the spark source mass spectrometer is useful for qualitative analyses and have made quantitative analyses of the elements $C_{s}$, In and $S_{n}$ by determination of their RSF's with a doped solution.?

A corparison of the photoplates from our two instruments was made. The most noticeable difference was that AI's plates showed none of the polymers that result from sodium oxidation occurring presumably while they load their samples into the mass spectrometer in argon. The principal differences in the plates result from the fact that the Westinghouse instrument has wider defining slits than the AI instrument. The larger ion beam that therefore passes through the Westinghouse instrument results in a somewhat quicker analysis but this could also account for considerable plate "fog" in the vicinity of the matrix line and results in poorer resolution. Westinghouse has been using a computer program to handle the data, and therefore they have been able to analyze more photoplates.

\section{PLANS FOR FUTURE WORK}

A. Equipment Modification

A data difitizing system consisting of a precision microphotometercomparator with a high-speed digital magnetic tape readout has been specified and ordered. This system will improve the accuracy of each analysis with numerous changes in the method of data processing. Corrections for background, Iine-width, and emulsion calibration will be performed completely and correctly by IBM 360-50 digital computer. The total time of analysis including sample preparation, sparking and data reduction is expected to be reduced by a factor of six. 
An "ion beam chopper" supplied by the mass spectrometer manufacturer has been ordered. Fulsed voltage applied to the two parallel plates serves to electronically deflect the lon beam away from the photoplate for any desired fraction of the total time. Several important advantages can be obtained. Most important the different deposits made on the photoplate in a sraded exposure can all be made under similar sparking conditions. Very short exposures will take longer and will therefore be easier to measure electronically and will represent a larger quantity of material, ironing out inhomogeneities. When the copper is pulsed in phase with the spark repetition rate, ions from the different portions of the spark pulse may be examined separately for variations.

Other small modifications that have proven useful to other spark source users, will be made as necessary. These include oscilloscope monitoring of the RF voltage "envelope" to facilitate control of the sparking conditions, and the attachment of a stereo microscope to the viewing port so that the exact position of the spark may be reset with respect to cross hairs.

\section{B. Evaluation}

Evaluation of the SSMS for its ability to, analyze alkali metals ill proceed along the following broad lines:

1. Determine the effects that numerous $R F$ spark parameters have on an analysis and attempt to optimize or control them. Such things as spark power, spark position, RF frequency, spark-gap width can influence the results.

2. Examine the effect of poor vacuum, of baking the source before each run, of cooling the electrodes, of cooling charcoal "vacuum" pads in the source in-relation to reproducibility of results, especially for C, $\mathrm{N}_{2}$ and $\mathrm{O}_{2}$ which can appear as surface contaminants.

3. Examine alternative methods of detection, photoplate development, plate-to-plate variation, influence of time between exposure and development, causes of photoplate "fog" and the effect of the "electron repeller" voltage. 
4. Determine what advantage there is of measuring line area, of includine multiple charged ions in the analysis and which method of plate calibration gives best reproducibility.

5. Find optimum sample handing procedures to minimize contamination, and obtain representative samples.

6. Perform repeated analyses using the doped sodium "standards." Small changes in the reproducibility as a result of changed parameter conditions will be examined on many plates with the use of the digitizing system.

The outcome of this work will show what conditions must be controlled for reproducible analyses and will give the detection limits for different elements, and the reproducibilities that are obtainable or that can be expected from the spark source mass spectrometric analysis of sodium and other alkalis.

\section{ACKNOWLEDGMENTS}

Many helpful and interesting discussions with R. I. McKission, R. L. Eichelberger and R. G. Breckenridge during the course of this work are greatfully acknowledged. This work was supported by the United States Atomic Energy Commission. 


\section{REFERENCES}

1. Willardson, R. K., and Socha, A. J., Report ARL 65-130 (1965).

2. Swift, P., as quoted by W. A. Wolstenholme, (AEI) Private Communication $(1966)$.

3. Kuptsis, M., (IBM) Yorktown Heights N. I., Private Communication (1966).

4. Stefani, R., Desjardins, M., Bourguillot, R., and Cornu, A. Chimie Analytique $47,6,(1365)$.

5. Farrar, H., and Tomlinson, R. H., Nucl. Physics 34, 367 (1962).

6. Sweeney, G. G., Berkey, E., and Hickam, W. M, Pittsburgh Conf. on Anal. Chem. \& Appl. Spectroscopy, Paper 198 (1968).

7. Berkey, E., Sweeney, G. G. and Hickam, W. M., Tran, Am, Nucl. Soc. 11. 113 (1968). 